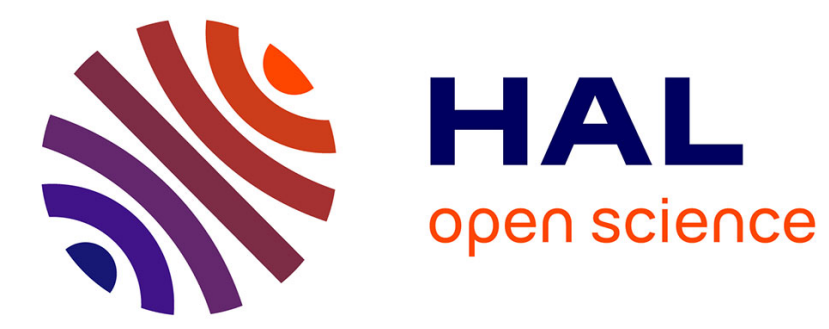

\title{
Does Uncertainty Deter Provision of Public Goods?
}

Béatrice Boulu-Reshef, Samuel H. Brott, Adam Zylbersztejn

\section{To cite this version:}

Béatrice Boulu-Reshef, Samuel H. Brott, Adam Zylbersztejn. Does Uncertainty Deter Provision of Public Goods?. 2017. halshs-01441053

\section{HAL Id: halshs-01441053 \\ https://shs.hal.science/halshs-01441053}

Submitted on 19 Jan 2017

HAL is a multi-disciplinary open access archive for the deposit and dissemination of scientific research documents, whether they are published or not. The documents may come from teaching and research institutions in France or abroad, or from public or private research centers.
L'archive ouverte pluridisciplinaire HAL, est destinée au dépôt et à la diffusion de documents scientifiques de niveau recherche, publiés ou non, émanant des établissements d'enseignement et de recherche français ou étrangers, des laboratoires publics ou privés. 


\section{Documents de Travail du

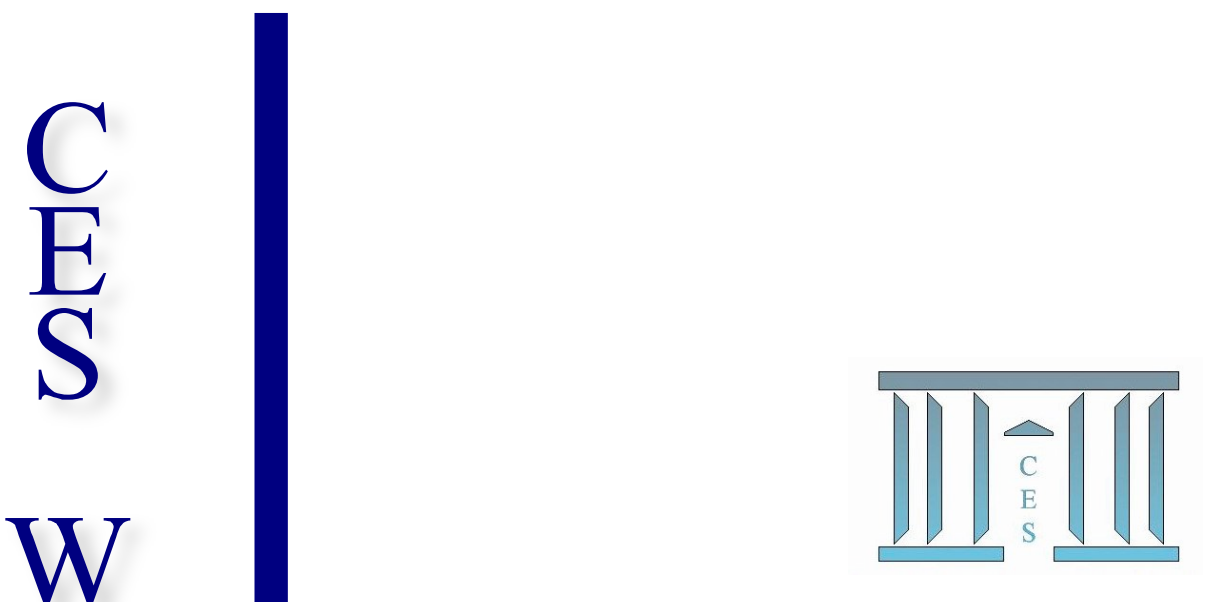

Does Uncertainty Deter Provision of Public Goods?

Béatrice Boulu-RESHEF, Samuel H. BROTT, Adam ZYLBERSZTEJN

2017.04

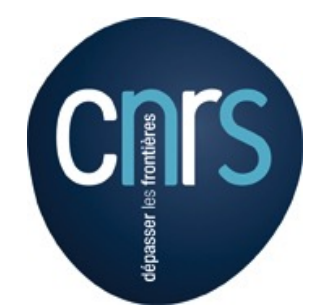




\title{
Does Uncertainty Deter Provision of Public Goods?
}

\author{
Béatrice Boulu-Reshef \\ Université Paris 1 Panthéon-Sorbonne, Centre d'Economie de la Sorbonne, UMR 8174, F-75647 \\ Paris cedex 13, France, beatrice.boulu-reshef@univ-paris1.fr \\ Samuel H. Brott \\ Berkeley Research Group, LLC, Washington, DC 20036, Etats-Unis, sbrott@thinkbrg.com \\ Adam Zylbersztejn \\ Univ Lyon, Université Lumière Lyon 2, GATE L-SE UMR 5824, F-69131 Ecully, France, \\ zylbersztejn@gate.cnrs.fr
}

We study a finitely repeated public goods game (based on the voluntary contribution mechanism) played under complete uncertainty about the marginal benefit of the public good relative to the private consumption (commonly known as the marginal per capita return): neither one's marginal per capita return nor other players' marginal per capita returns are known at the time of decisionmaking. We show that contributions are equivalent when the rate of return is predetermined and when it is uncertain, and display a similar decay over time. Combined with the previous experimental findings, our results suggest that the cooperation in public goods games is sensitive to the source of uncertainty about marginal per capita return.

Key words Cooperation, uncertainty, voluntary contribution mechanism, public good, expected return.

JEL H41 D81 C91 C92 


\section{Introduction}

The voluntary contribution mechanism (hereafter, VCM) is a simple and elegant way to capture the social dilemma - a trade-off between individual and group interest - underlying the production of public goods. Over the years, investigating the determinants of public good provision via voluntary contributions experiments has become a classic topic in economics and other social sciences (Marwell and Ames, 1979; Kim and Walker, 1984; Ledyard, 1995).

Nonetheless, certain features of standard VCM experiments might call their external validity into question. For instance, the marginal per capita return on each unit of wealth contributed to the public good (hereafter MPCR), i.e. the marginal benefit of the public good relative to the private consumption, is common knowledge in numerous laboratory experiments. ${ }^{1}$ However, this absence of uncertainty may not be a general feature of real world public goods. This might be the case because one's needs cannot be defined with certainty (like the demand for health care), or because the value of a public good only becomes known ex post (like the value of education in a newly established public school or the value of a newly opened public park). In addition, the value of a public good for the other individuals in a group may not be known to those who are in a position to contribute to a public good and these values may vary over time.

Whether and how uncertain MPCR may affect the provision of public goods remains an open question. Existing experimental methodology is based on partial uncertainty (related either to personal MPCR or others' MPCRs) and yields mixed results. For instance, the design of Fisher et al. (1995) combines uncertainty about the distribution of MPCR given to other players with certainty about one's own MPCR. In Fischbacher et al. (2014), in turn, the distribution of MPCRs

1 Note that the MPCR has to be lower than the return from consumption (i.e. from keeping the unit for oneself) to generate the social dilemma. The details of our experimental VCM game can be found in Section 3. 
in a group is common knowledge, while one's own MPCR remains uncertain. The contribution levels are found to be neutral to the first type of partial uncertainty, and diminished slightly due to the second type of partial uncertainty.

In this paper, we complement this line of literature by investigating the effect of uncertainty in a novel way and combine both types of partial uncertainty in what we call a complete uncertainty environment. In this setting, all group members either have a predetermined MPCR that is known ex ante (Certainty treatment), or face a uniformly distributed and mean-preserving MPCR that is drawn ex post and iid across rounds and individuals (Uncertainty treatment).

The main results are the following. First, we confirm the classic finding that contributions tend to diminish over time in the Certainty treatment. Second, we show that uncertain returns to cooperation do not negatively affect provision to the public good, and that our subjects well comprehend the random nature of MPCR.

\section{Related literature}

A seminal study by Fisher et al. (1995) is the first attempt to introduce uncertainty about MPCR in what we call a standard VCM game where the decision environment is repeated over multiple rounds with multiple players matched in a partner setting and facing a quasi-continuous action set. Each player knows his MPCR which may equal either 0.30 and 0.75 . In addition, in the homogenous treatments all group members have the same MPCR (which is common knowledge), whereas in the heterogeneous treatments MPCRs involve uncertainty: they might vary within a group and their exact distribution is unknown to players. Fisher et al. find that while players react

to the changes in their own MPCR, their contributing behavior is neutral to the presence of uncertainty about others' MPCRs. In a recent study, Fischbacher et al. (2014) swap the sources of 
uncertainty and show that uncertainty about personal MPCR slightly (yet significantly) decreases contributions when MPCR is heterogeneous within a group and has a predetermined distribution that is common knowledge.

In other related experiments, Dickinson (1998) and Gangadharan and Nemes (2009) use the standard VCM framework to study uncertainty about receiving the return from the public good. They find that this type of uncertain environment also decreases contributions to the public good. In addition, Stoddard (2015) suggests that this effect may be sensitive to the way uncertainty comes about: moving from certain to uncertain benefits from public goods is found to decrease contributions.

Finally, our endeavor also echoes Levati et al. (2009). Their control treatment consists of a quasicontinuous-action-space two-person prisoner's dilemma game with a 0.75 MPCR. In their "imperfect information" treatment, it is common knowledge that the MPCR is identical for both players and may equal either 0.4 or 1.1 (with the same probability). Hence, the expected marginal benefits from cooperation are the same as in the control treatment which makes this game a social dilemma in expectation. However, none of the possible scenarios is a social dilemma per se: the MPCR is either as low so as to make any cooperation unbeneficial, or as high so as to make contribution to the public good a dominant strategy even for selfish players. Herein, we refine the framework of Levati et al. (2009) by maintaining the social dilemma environment under all information structures, and extend it to the standard VCM framework applied in the previous studies reviewed above.

\section{Our method}


We study the effect of uncertainty on the return to cooperation in a conventional voluntary contribution game played for 10 rounds. Each participant is first randomly assigned to a group of four players that remains unchanged throughout the experiment. At the beginning of each round, every player holds an endowment of $E=10$ tokens and decides on his personal contribution $\left(c_{i}\right)$ to the public good. The individual return per round is defined as $\pi_{i}=\alpha_{1}\left(E-c_{i}\right)+\alpha_{2} C$ where $C$ is the total group contribution, $\alpha_{1}$ is the marginal benefit from keeping a token to oneself, while $\alpha_{2}$ (with $\left.\alpha_{2}<\alpha_{1}\right)$ is the MPCR from a contributed token.

Standard predictions for finitely repeated VCM are straightforward. Since the personal return to each unit of wealth contributed to the public good is lower than the benefit from keeping it to oneself, the Nash equilibrium for all individuals is to contribute nothing. However, individual interest stands at odds with social welfare: Pareto-improvement may be achieved if all players contribute their entire endowment. This prediction also holds for a repeated game.

Within this standard framework, we implement two different treatments. In the Certainty treatment, we have $\alpha_{1}=0.1$ and $\alpha_{2}=0.0525$. In the Uncertainty treatment, players must contribute before learning about their MPCR. It is common knowledge that each player's MPCR in a given round of the game is an independent draw from a uniform distribution U[0.03, 0.075]. This calibration guarantees that the latter treatment is mean-preserving with respect to the previous one. $^{2}$

The experiment was carried out at the Veconlab at the University of Virginia with students who signed-up to be part of the participant pool. The experiment was programmed and conducted with the experiment software z-Tree (Fischbacher 2007). We ran 8 sessions (4 per treatment) involving

2 The empirical average MPCR observed in our experiment equals 0.0529 -- fairly close to the expected value of 0.0525 . 
a total of 96 participants. Each session consisted of 12 participants divided into three fixed group of four players. Each session proceeded as follows. Paper instruction sheets were distributed and read aloud. ${ }^{3}$ It was common knowledge that the experiment consisted of 10 rounds. The MPCR was presented in terms of the token-USD exchange rate. Each token kept to oneself was worth $\$ 0.10$ in both treatments. Each token contributed to the public good in the Certainty treatment brought $\$ 0.0525$ to every group member. In the Uncertainty treatment, the value of a contributed token could vary uniformly between $\$ 0.03$ and $\$ 0.075$. Next, subjects were asked to answer practice questions to ensure full comprehension of these rules. Finally, the first round of the experimental game started. At the end of each round, each participant learned about his/her personal realization of the MPCR (but not other players' realizations), the total group contribution, as well as his/her payoff (in tokens) in that round. At the end of the experiment, individual gains were totaled over 10 rounds. Payments in USD were made in cash to each participant. Sessions lasted about one hour with an average payoff of $\$ 20.40$, including a show-up fee of $\$ 6.00$.

\section{Results}

Our empirical results are as follows. First, we confirm the classic behavioral phenomenon observed in the vast majority of experiments using a repeated VCM game: a systematic decay of contributions over time in the Certainty treatment. More importantly, we also show that this behavioral pattern also holds (with a similar magnitude) in our Uncertainty treatment. Second, we investigate the effect of experienced randomness on behavior in an uncertain world. We robustly reject the hypothesis that past MPCRs affect players' contributions: neither the most recent realization of random MPCR, nor the accumulated individual experience with its past realizations

3 Instructions for both treatments are provided in the online supplementary material. 
can predict players' behavior. This suggests that our subjects have a rational perception of randomness in the experiment. Together, these two findings point to the conclusion that players' behavior is neutral to the presence of uncertainty about MPCR. Our results are consistent with what could be expected from a pool of risk neutral subjects in the sense that uncertainty about MPCR has no impact on behavior. This stands in line with an observation by Harrison and Rutström (2008) that the degree of risk aversion among experimental subjects is usually modest.

Result 1. Aggregate mean contributions in both treatments are not statistically different. Furthermore, both treatments reveal similar aggregate dynamics: a significant decay of contributions over time.

Support. The estimates of Model 1 reported in Table 1 suggest that the difference between the mean contributions in both treatments is not statistically significant $\left(\mathrm{H}_{0}: \mathrm{b}_{1}=0, \mathrm{p}=0.770\right){ }^{4}$

Furthermore, Figure 1 suggests that the average contribution in both treatments decreases over time. This observation is confirmed by Model 2 reported in Table 1 . The null hypothesis that Round has no effect on the average contribution is rejected in both the Certainty treatment $\left(\mathrm{H}_{0}\right.$ : $\left.\mathrm{b}_{2}=0, \mathrm{p}<0.001\right)$ and the Uncertainty treatment $\left(\mathrm{H}_{0}: \mathrm{b}_{2}+\mathrm{b}_{3}=0, \mathrm{p}=0.034\right)$. Furthermore, the difference between the effects of the Round variable in both treatments is not significantly different from zero $\left(\mathrm{H}_{0}: \mathrm{b}_{3}=0, \mathrm{p}=0.173\right)$.

\section{INSERT TABLE 1 HERE \\ INSERT FIGURE 1 HERE}

4 Left-censored tobit estimation of the models from Tables 1 and 2 yields similar results as our OLS estimation. 
Result 2. Individual contributions do not depend on players' past experience with stochastic MPCRs.

Support. Models presented in Table 2 uses the data from our Uncertainty treatment to investigate the relationship between individual contributions and the realizations of MPCRs experienced in the past. The latter is measured in two distinct ways: as MPCR observed in the previous round and the cumulative average of all MPCRs observed since the first round. ${ }^{5}$ They both suggest that there is no significant effect of the historical information about MPCR on present behavior: the p-values from the tests of nullity of coefficients $b_{1}$ and $b_{2}$ range from 0.718 to 0.953 across the three models, and their joint nullity in Model 3 cannot be rejected $(\mathrm{p}=0.930)$.

\section{INSERT TABLE 2 HERE}

\section{Conclusion}

Understanding the effect of uncertainty on the provision of public goods is an important empirical challenge in public economics. This paper uses experimental evidence to determine the effect of complete uncertainty about marginal returns to public goods on contributions in a standard setting of a finitely repeated voluntary contribution mechanism. We report no significant differences in individuals' contributions between a treatment where this rate of return is fixed and commonly known, and a treatment where it is determined individually and randomly in every round using a mean-preserving uniform distribution, and becomes known ex post.

5 As suggested by a referee, the past experience with random MCPRs can be also related to gains of losses relative to the theoretical expected value. We have also estimated an alternative specification of the model in which the independent variables are: a dummy set to 1 if the MPCR in $t-1$ is below the expected value of 0.0525 , and an accumulated proportion of such realizations between rounds 1 and $t-1$. This new model fully confirms our finding that behavior is neutral to the experience with random MPCRs. 
Accumulated evidence from different uncertainty settings suggests that cooperation in public goods games is sensitive to the source of uncertainty. A null result from Fisher et al. (1995) arises in an environment with uncertainty about the distribution of MPCR amongst others, but without uncertainty about one's own MPCR. Fischbacher et al. (2014) observe a negative effect of uncertainty about personal MPCR on individual contributions when the distribution of MPCRs within groups is predetermined and known to players. Levati et al. (2009) report similar effect when MPCR is random and homogenous within a group. Herein, we show that a complete uncertainty environment that combines two kinds of partial uncertainty -- about own MPCR and the distribution of MPCRs in a group -- does not harm cooperation in a public goods game. Altogether, this growing set of divergent experimental results calls for further research on the topic. 


\section{References}

Dickinson, D.L. (1998) 'The voluntary contributions mechanism with uncertain group payoffs' Journal of Economic Behavior \& Organization 35(4): 517-533.

Fischbacher, U. (2007) 'z-Tree: Zurich Toolbox for Ready-made Economic Experiments' Experimental Economics 10(2): 171-178.

Fischbacher, U., S. Schudy, and S. Teyssier (2014) 'Heterogeneous Reactions to Heterogeneity in Returns from Public Goods' Social Choice and Welfare 43(1): 195-217.

Fisher, J., R.M Isaac, J.W. Schatzberg, J.M. Walker (1995) 'Heterogenous Demand for Public Goods: Behavior in the Voluntary Contributions Mechanism’ Public Choice 85(3/4): 249266.

Harrison, G. W. and E. E. Rutström, (2008) "Risk Aversion in the Laboratory”, Ed. James C. Cox and Glenn W. Harrison, in Research in Experimental Economics, Volume 12, pp. 41 196.

Gangadharan, L and V. Nemes (2009) 'Experimental analysis of risk and uncertainty in provisioning private and public goods' Economic Inquiry 47(1): 146-164.

Kim, O. and M. Walker (1984) 'The Free Rider Problem: Experimental Evidence’ Public Choice 43(1): 3-24.

Ledyard, J. O., (1995). Public goods: a survey of experimental research. In J. H. Kagel, \& A. E. Roth (Eds.) The handbook of experimental economics (Chap. 2, pp. 111-194). Princeton: Princeton University Press.

Levati, M.V., A. Morone, and A. Fiore (2009) 'Voluntary Contributions with Imperfect Information: An experimental Study’ Public Choice 138(1/2): 199-216. 
Marwell, G. and R.E. Ames (1979) 'Experiments on the Provision of Public Goods. I. Resources, Interest, Group Size, and the Free-Rider Problem’ American Journal of Sociology 84(6): 1335-1360.

Stoddard, B.V. (2015) 'Probabilistic Production of a Public Good' Economics Bulletin 35(1): 3752. 
Table 1. Contributions across treatments and rounds: OLS regression analysis

\begin{tabular}{lll}
\hline & Model 1 & Model 2 \\
Constant $\left(\mathrm{b}_{0}\right)$ & $3.860^{* * *}$ & $5.568^{* * *}$ \\
& $(0.667)$ & $(0.912)$ \\
Uncertainty $\left(\mathrm{b}_{1}\right)$ & 0.279 & -0.493 \\
& $(0.945)$ & $(1.184)$ \\
& & $-0.310^{* * *}$ \\
Round $\left(\mathrm{b}_{2}\right)$ & & $(0.066)$ \\
& & 0.140 \\
Round X Uncertainty $\left(\mathrm{b}_{3}\right)$ & & $(0.100)$ \\
& & 960 \\
$\mathrm{~N}$ & 960 & 0.043 \\
$\mathrm{R}^{2}$ & 0.002 & $<0.001$ \\
Prob $>\mathrm{F}$ & 0.770 &
\end{tabular}

Note. OLS estimates in both models are based on observations coming from 10 rounds of both treatments. Uncertainty is a dummy variable set to 1 for Uncertainty treatment (and 0 otherwise), Round represents the consecutive rounds of the game. Standard errors are clustered at the group level (12 groups per treatment, 24 in total) and corrected using a leave-one-out jackknife procedure; their estimates are provided in parentheses underneath the coefficient estimates. 
Figure 1. The evolution of aggregate mean contributions across treatments

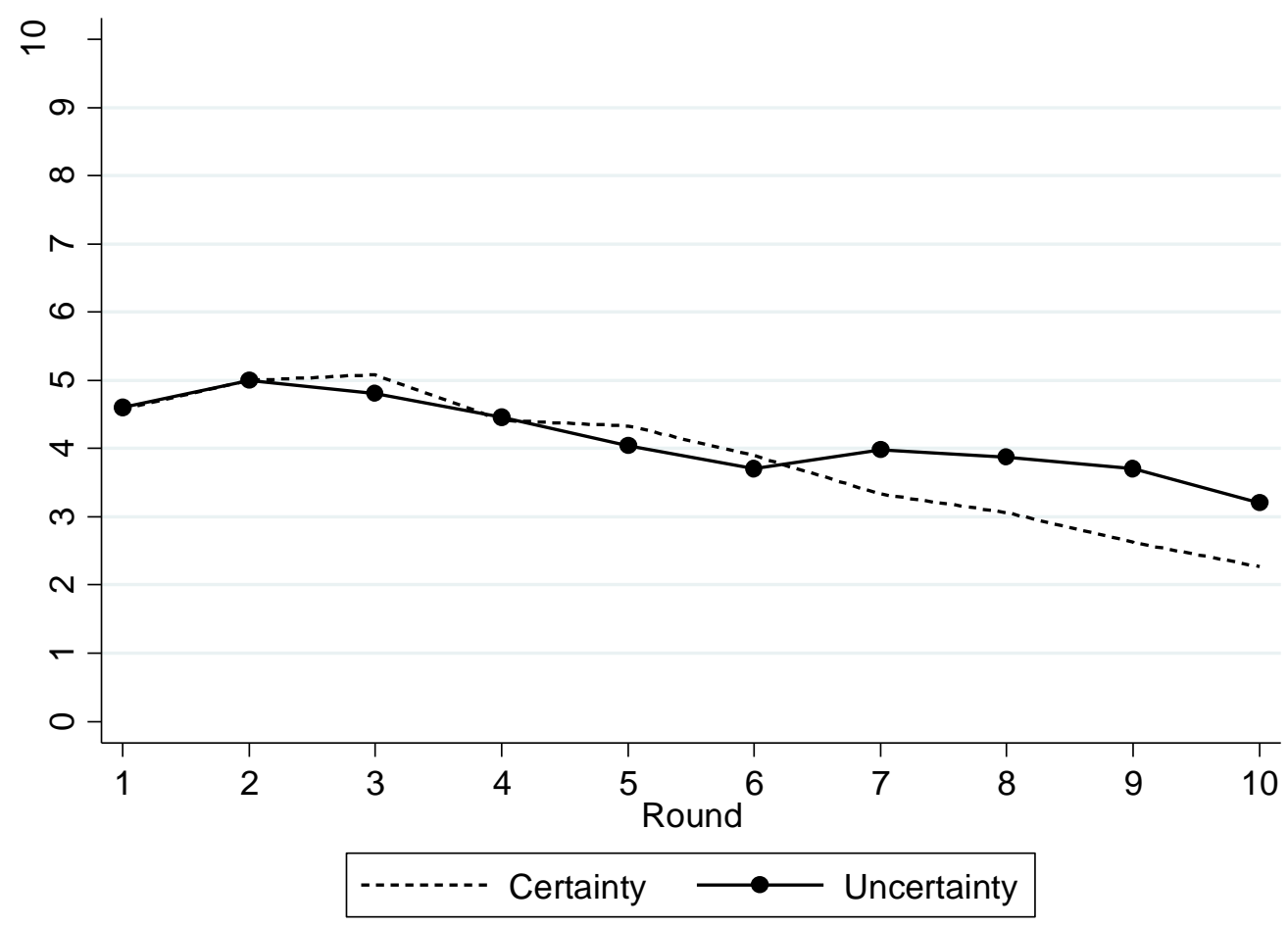

Table 2. Individual contributions and the historical information on MPCR in the Uncertainty treatment: OLS regression analysis

\begin{tabular}{llll}
\hline & Model 1 & Model 2 & Model 3 \\
Constant $\left(\mathrm{b}_{0}\right)$ & $3.981^{* * *}$ & 4.450 & 4.491 \\
& $(0.775)$ & $(3.120)$ & $(3.200)$ \\
MPCR in round $t-l\left(\mathrm{~b}_{1}\right)$ & 0.202 & & 0.584 \\
& $(1.432)$ & & $(1.578)$ \\
Cumulative average MPCR & & -0.678 & -1.335 \\
before round $t\left(\mathrm{~b}_{2}\right)$ & & $(5.847)$ & $(6.961)$ \\
$\mathrm{N}$ & 432 & 432 & 432 \\
$\mathrm{R}^{2}$ & $<0.001$ & $<0.001$ & $<0.001$ \\
Prob $>\mathrm{F}$ & 0.890 & 0.910 & 0.930 \\
\hline
\end{tabular}

Note. OLS estimates in both models are based on observations coming from 10 rounds of Uncertainty treatment. Standard errors are clustered at the group level (12 groups per treatment, 24 in total) and corrected using a leave-one-out jackknife procedure; their estimates are provided in parentheses underneath the coefficient estimates. 
Acknowledgments We would like to thank Charles A. Holt, Nicolas Jacquemet and Jean-Marc Tallon for their help and suggestions. We also thank two anonymous referees for their useful comments and suggestions. Samuel Brott thanks the financial support of the Small Research and Travel Grant and the Marshall Jevons Fund of the University of Virginia. Part of this research was performed within the framework of the LABEX CORTEX (ANR-11-LABX-0042) of Université de Lyon, within the program Investissements d'Avenir (ANR-11-IDEX-007) operated by the French National Research Agency (ANR). 